\title{
Enzyme Inhibitors and Activators
}

\author{
Olga D. Lopina
}

Additional information is available at the end of the chapter

http://dx.doi.org/10.5772/67248

\begin{abstract}
Enzymes are very effective biological catalysts that accelerate almost all metabolic reactions in living organisms. Enzyme inhibitors and activators that modulate the velocity of enzymatic reactions play an important role in the regulation of metabolism. Enzyme inhibitors are also useful tool for study of enzymatic reaction as well as for design of new medicine drugs. In this chapter, we focused on the properties of enzyme inhibitors and activators. Here we present canonical inhibitor classification based on their kinetic behavior and mechanism of action. We also considered enzyme inhibitors that were used for design of various types of pharmacological drugs and natural inhibitors as a plausible source for design of future drugs. Mechanisms of action of enzyme activators and some features of allosteric modulators are considered.
\end{abstract}

Keywords: enzyme conformational mobility, classification of enzyme inhibitors, enzyme activators and inhibitors, mechanism of action

\section{Introduction}

Enzymes (E) is a group of biologically active polymers (mainly proteins) that catalyze almost all metabolic reactions in all living organisms. Enzymes are able to accelerate chemical reaction dividing it into separate steps. Because each step of enzymatic reaction has a value of activation energy significantly lower than the value of activation energy for the same chemical reaction, enzymes can increase a rate of reaction $10^{6}-10^{18}$ folds. According to contemporary hypothesis, high conformational mobility of the enzymes allows them to adopt their active sites to substrate(s) and intermediates of the reaction in the best way [1,2]. Multiple conformers of enzymes with close values of free energy preexist in the solution simultaneously. Along the reaction way, a conformer is picked out, the structure of which can stabilize definite intermediate that makes a reaction more thermodynamically profitable [3]. 
This hypothesis is supported by unsuccessful attempts to create catalytically effective low molecular enzymes having needed active site (molecular mass should be higher than $10,000 \mathrm{Da}$ ) or enzyme with correct active site but with restricted conformational mobility (antibodies with needed active site, so-called abzymes [4]). In the context of described hypothesis, enzyme inhibitors being bound to the enzyme "freeze" it in definite conformation that makes impossible selection of conformers participating in numerous steps of enzymatic reaction. By this way, inhibitors stop enzymatic reaction.

On the other hand, the binding of enzyme activators may lead to the creation of more profitable conformers that can be more effective in carrying out definite steps of the reaction. Therefore, they will accelerate enzymatic reaction. Taking into account this information about enzymes in this chapter, we consider contemporary knowledge about enzyme inhibitors and activators.

\section{Enzyme inhibitors}

\subsection{Definition, classification, and main properties}

Enzymes are different chemical compounds that are combined into a group because of their only feature - they can suppress enzyme activity. The suppression of the activity is the result of the binding of inhibitor to the enzyme molecule that arrests catalytic reaction. Because enzymes catalyze most part of chemical reactions in living organisms, the enzyme inhibitors play an important role in the development of different sciences (biochemistry, physiology, pharmacy, agriculture, ecology) as well as the technologies (production of pharmaceutical drugs, insecticides, pesticides, chemical weapons, etc.).

Many pharmacological drugs are enzyme inhibitors. The group of well-known pharmaceutical agents with name nonsteroidal antiinflammatory drugs (NSAIDs) includes inhibitors of enzyme cyclooxygenase that catalyzes a first step of synthesis of biologically active compounds prostaglandins that are responsible for the development of pain, inflammation, fever, contraction of smooth muscle, formation of blood clots, and others [5].

All inhibitors may be combined in different groups in accordance with their chemical structure: ions of metals $\left(\mathrm{Hg}^{+}, \mathrm{Fe}^{2+}, \mathrm{Cu}^{+}, \mathrm{Pb}^{2+}\right)$, organic compounds (e.g., N-ethylmaleimide, diisopropyl phosphofluoridate, oligomycin), and large bioorganic molecules, (peptides, proteins, etc). However, this classification does not reflect mechanism of their interaction with enzyme.

In accordance with the mode of action, enzyme inhibitors may be divided into two different groups (reversible and irreversible inhibitors). Reversible inhibitors, in turn, may be combined in four groups in accordance with kinetic behavior (competitive, uncompetitive, noncompetitive, and mixed inhibitors) [6].

The mechanism of action of enzyme inhibitors includes a step of enzyme-inhibitor complex formation (EI complex) that has no (or low) enzyme activity. An irreversible inhibitor dissociates from this complex very slow because it is tightly bound to the enzyme. Mainly this mode of inhibition is connected with the formation of covalent bond or hydrophobic interaction between 
enzyme and inhibitor. Irreversible inhibitors usually react with the enzyme and change it chemically. These inhibitors often contain reactive functional groups that modify amino acid residues of enzyme that are essential for its activity. They also can provide inhibition affecting the enzyme conformation. An example of irreversible inhibitor is N-ethylmaleimide that covalently interacts with $\mathrm{SH}$-group of cysteine residues of enzyme molecules, like peptidase (insulin-degrading enzyme) [7], 3-phosphoglyceraldehyde dehydrogenase [8], or hydrophobic compound from group of cardiotonic steroids that at the last bind to $\mathrm{Na}, \mathrm{K}$-ATPase using hydrophobic interactions [9]. Another well-known irreversible inhibitor is diisopropyl phosphofluoridate that modifies $\mathrm{OH}$-group of serine residue in active site of such enzymes as chymotrypsin and other serine proteases $[10,11]$ or acetylcholine esterase in cholinergic synapsis of the nervous system being a potent neurotoxin [12]. Inhibition of this enzyme causes an increase in the acetylcholine neurotransmitter concentration that results in muscular paralysis and death. Inhibitor of cyclooxygenase aspirin (acetyl salicylic acid) covalently modifies $\mathrm{OH}$-group of serine residue located in a close proximity to the active site of cyclooxygenase [13].

Irreversible inhibition is different from irreversible enzyme inactivation. Irreversible inhibitors are generally specific for one class of enzymes and do not inactivate all proteins. In contrast to denature agents such as urea, detergents do not destroy protein structure but specifically alter the active site of the target enzyme.

Consequently because of tight binding, it is difficult to remove an irreversible inhibitor from the EI complex after its formation [14]. So, we can refer some chemical compound to irreversible enzyme inhibitor, if after the formation of EI complex, the dilution of it with significant amount of water (100-200 excess) does not restore enzyme activity.

Irreversible inhibitors display time-dependent loss of enzyme activity. Interaction of irreversible inhibitor with enzyme is a bimolecular reaction:

$$
\mathrm{E}+\mathrm{I} \stackrel{k_{I}}{\longrightarrow} \mathrm{EI}
$$

where $\mathrm{E}$ is enzyme, I is inhibitor, EI is complex of enzyme-inhibitor, and $k i$ is a constant of the velocity of this reaction.

However, usually the action of irreversible inhibitors is characterized by the constant of observed pseudo-first order reaction under conditions when concentration of inhibitor is significantly higher than concentration of the enzyme. The value of pseudo-first order rate of inhibition may be measured by plotting of the ln of enzyme activity (in \% relatively enzyme activity in the absence of inhibitor) vs. time. Tangent of slope angle of straight line obtained by this way will be equal to value of constant of pseudo-first order inhibition. The value of rate constant of bimolecular reaction for irreversible inhibition may be then calculated by dividing the obtained value of constant of pseudo-first order reaction per inhibitor concentration.

Reversible inhibitor binds to the enzyme reversibly [6, 14]. It means that there is equilibrium between the formation and dissociation of EI complex:

$$
\mathrm{E}+\mathrm{I} \underset{k_{2}}{\stackrel{k_{1}}{\leftrightarrow}} \mathrm{EI}
$$


where $k_{1}$ is a constant of the velocity of direct reaction and $k_{2}$ is a constant of the velocity of reverse reaction. The effect of reversible inhibitors is characterized by the constant of dissociation of EI complex that is equal to [E] [I]/[EI] or $k_{1} / k_{2}$.

Usually reversible inhibitor binds to the enzymes using non-covalent interactions such as hydrogen or ionic bonds. Different types of reversible inhibition are produced depending on whether these inhibitors bind to the enzyme, the enzyme-substrate complex, or both.

One type of reversible inhibition is called competitive inhibition. In this case, there are two types of complexes: enzyme inhibitor (EI) and enzyme substrate (ES); complex EI has no enzyme activity. The substrate and inhibitor cannot bind to the enzyme at the same time. This inhibition may be reversed by the increase of substrate concentration. However, the value of maximal velocity (Vmax) remains constant. The value of apparent $\mathrm{Km}$ will increase; however, the value of maximal velocity (Vmax) remains constant (Figure 1). It can be competitive inhibition not only in relation to substrate but also to cofactors, as well as to activators.
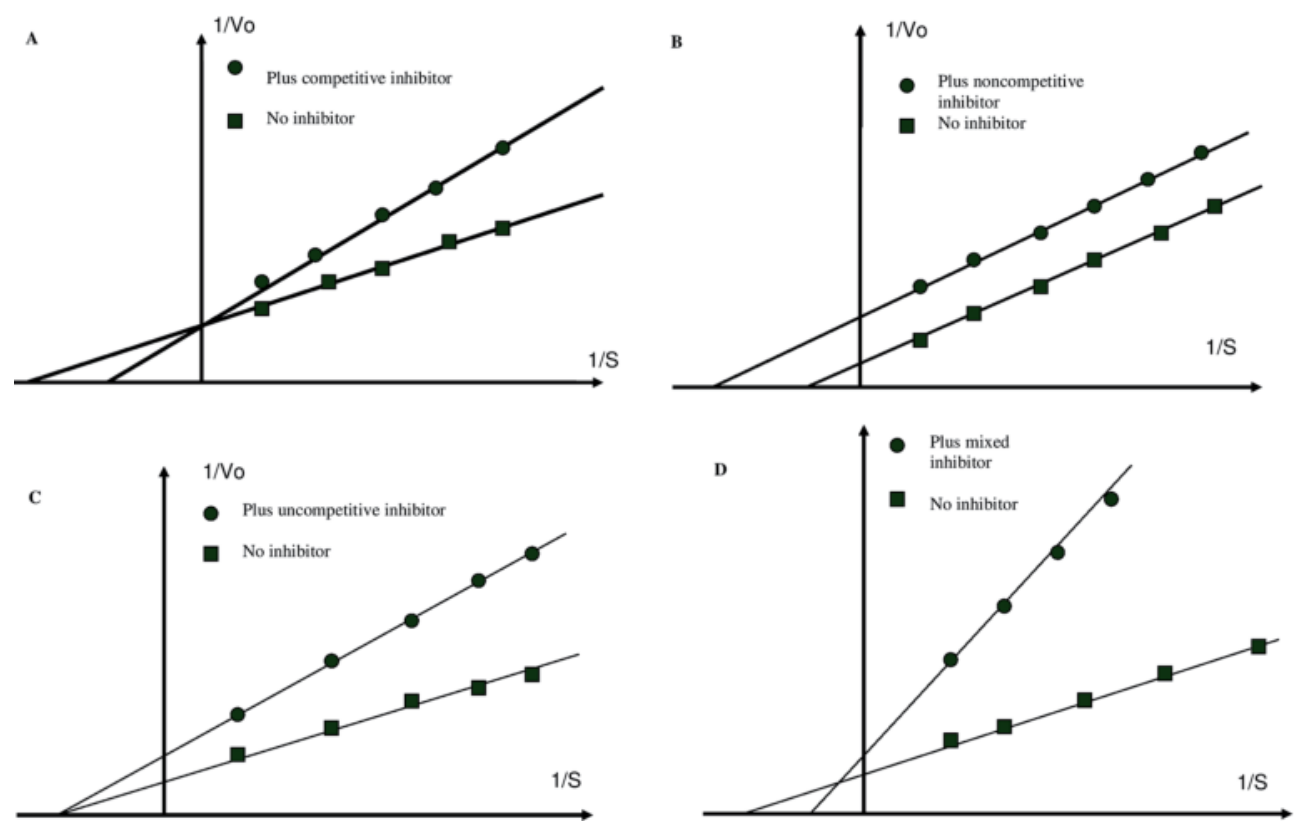

Figure 1. Kinetic test for reversible inhibitor classification. Double reciprocal plot $\left(1 / \mathrm{V}_{\mathrm{o}}\right) \mathrm{vs}$. (1/s) for competitive (A), uncompetitive (B), noncompetitive (C), and mixed (D) enzyme inhibition [14].

Another type of reversible inhibition is uncompetitive inhibition. In this case, the inhibitor binds only to the substrate-enzyme complex; it does not interfere with the binding of substrate with active site but prevents the dissociation of complex enzyme substrate: it resulted in the dependence of the inhibition only upon inhibitor concentration and its Ki value. This type of inhibition results in Vmax decrease and Km decrease (Figure 1, B). 
The third type of inhibition is noncompetitive. This type of inhibition results in the inability of complex enzyme (E) inhbitor (I) substrate (EIS) to dissociate giving a product of reaction. In this case, inhibitor binds to E or to ES complex. The binding of the inhibitor to the enzyme reduces its activity but does not affect the binding of substrate. As a result, the extent of the inhibition depends only upon the concentration of the inhibitor. In this case, Vmax will decrease, but $\mathrm{Km}$ will remain the same (Figure 1, C).

In some cases, we can see mixed inhibition, when the inhibitor can bind to the enzyme at the same time as to enzyme-substrate complex. However, the binding of the inhibitor effects on the binding of the substrate and vice versa. This type of inhibition can be reduced, but not overcome by the increase of substrate concentrations. Although it is possible for mixed-type inhibitors to bind in the active site, this inhibition generally results from an allosteric effect of inhibitor (see below). An inhibitor of this kind will decrease Vmax, but it will increase Km (Figure 1, C).

Special case of enzyme inhibition is inhibition by the excess of substrate or by the product. This inhibition may follow the competitive, uncompetitive, or mixed patterns. Inhibition of enzyme by its substrate occurs when a dead-end enzyme-substrate complex forms. Often in the case of substrate inhibition, a molecule of substrate binds to active site in two points (e.g., by the "head" and by the "tail" of molecule). At high concentrations, two substrate molecules bind in active site the following manner: one substrate molecule binds using the "head" and another molecule using the "tail." This binding is nonproductive and substrate cannot be converted to the product (Figure 2). An example of such inhibition is inhibition of acetyl cholinesterase by the excess of acetylcholine [15].

A

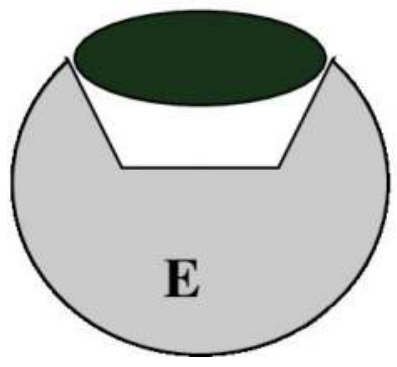

B

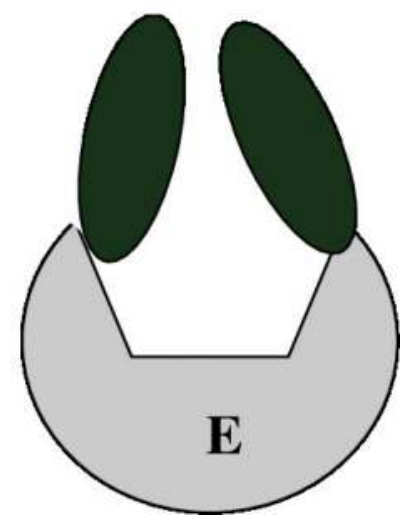

Figure 2. Enzyme inhibition by substrate. Productive binding of one substrate molecule with two points of enzyme active site (A) and unproductive binding of two substrate molecules with the same site (B).

Competitive inhibitors mainly interact with enzyme active site preventing binding of real substrate. Classical example of competitive inhibition is inhibition of fumarate hydratase by maleate that is a substrate analog (Figure 3). Enzyme is highly stereospecific; it catalyzes the 
hydration of the trans-double bound of fumarate but not maleate (cis-isomer of fumarate). Maleate binds to active site with high affinity preventing the binding of fumarate. Despite the binding maleate to active site, it cannot be converted into the product of reaction. However, maleate occupies active site making it inaccessible for real substrate and providing by this way the inhibition [16].

$\mathbf{A}$

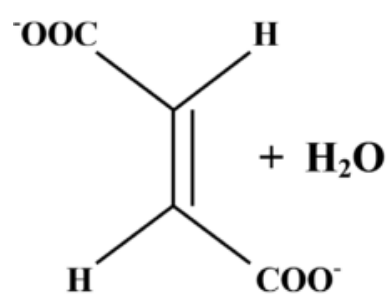

Fumarate

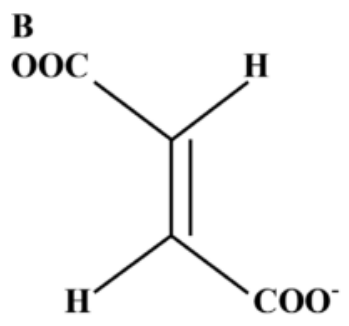

Fumarate

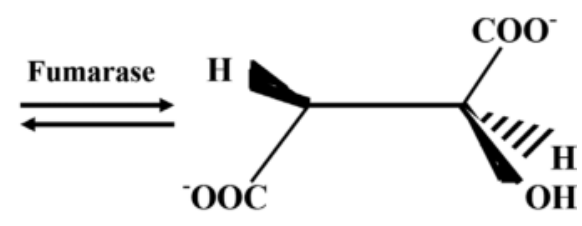

S-malate

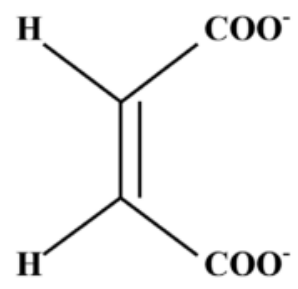

Maleate

Figure 3. Example of enzyme competitive inhibitors. A reaction catalyzing by fumarate hydratase (A) and comparison of structure of fumarate (substrate of reaction) and maleate (enzyme competitive inhibitor) (B) [16].

Some reversible inhibitors bind so tightly to the enzyme that they are essentially irreversible. It is known that proteolytic enzymes of the gastrointestinal tract are secreted from the pancreas in an inactive form. Their activation is achieved by restricted trypsin digestion of proenzymes. To stop activation of proteolytic enzymes, the pancreas produces trypsin inhibitor. It is a small protein molecule (it consists of 58 amino acid residues) [17]. This inhibitor binds directly to trypsin active site with $\mathrm{Kd}$ value that is equal to $0.1 \mathrm{pM}$. The binding is almost irreversible; complex EI does not dissociate even in solution of $6 \mathrm{M}$ urea. The inhibitor is a very effective analog of trypsin substrates; amino acid residue Lys-15 of inhibitor molecule interacts with aspartic residue located in a pocket of enzyme surface destined for substrate binding, thereby preventing its binding and conversion into the product (Figure 4). 


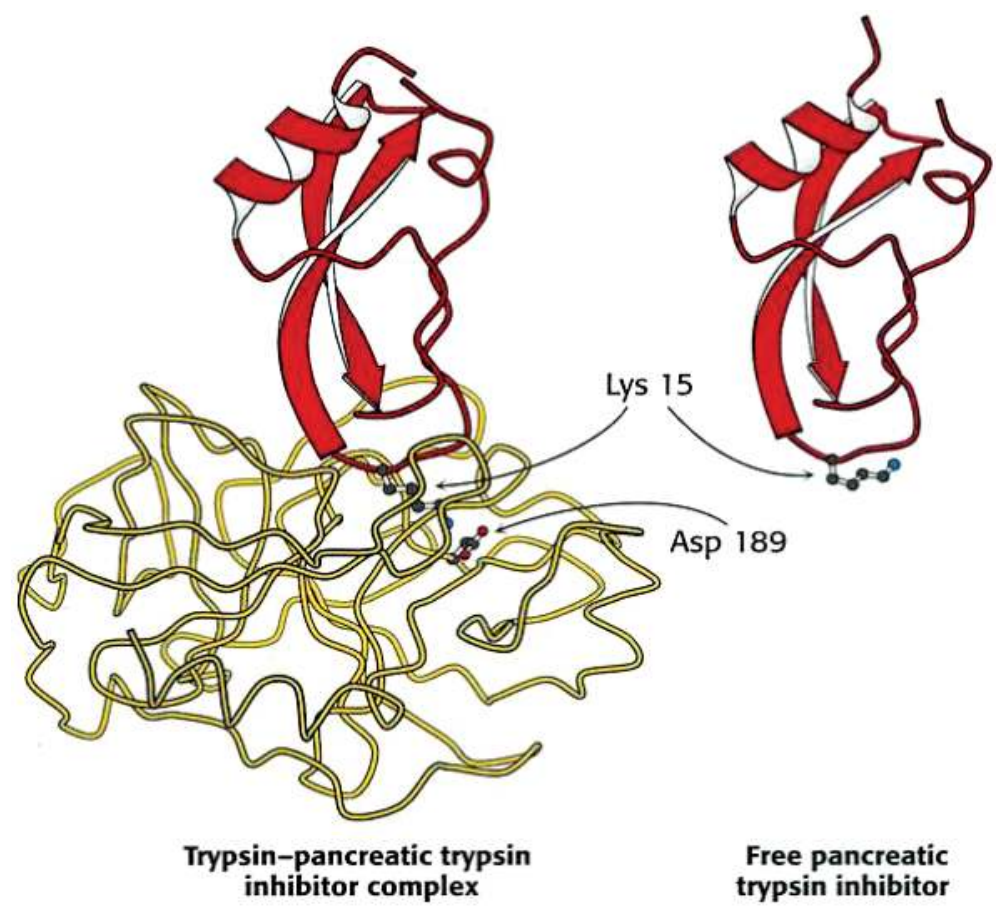

Figure 4. Structure of complex pancreatic trypsin inhibitor-trypsin and free trypsin inhibitor [17].

\subsection{Irreversible inhibitors as a tool for study of enzymes: enzyme active sites labeling by} irreversible inhibitors

To obtain information concerning the mechanism of enzyme reaction, we should determine functional groups that are required for enzyme activity and located in enzyme active site. First approach is to reveal a 3D structure of enzyme with bound substrate using X-ray crystallography. Alternative and/or additional approach is to use group-specific reagent that simultaneously is irreversible inhibitor of the enzyme. It can covalently bind to reactive groups of enzyme active site that allow to elucidate functional amino acid residues of the site. Modified amino acid residues may be found later after achievement of complete enzyme inhibition, enzyme proteolysis, and identification of labeled peptide(s).

Irreversible inhibitors that can be used with this aim may be divided into two groups: (1) group-specific reagents for reactive chemical groups and (2) substrate analogs with included functional groups that are able to interact with reactive amino acid residues. These compounds can covalently modify amino acids essential for activity of enzyme active site and in such a manner can label them.

One from the most known group-specific reagent that was used to label functional amino acid residue of enzyme active site of protease chymotrypsin was diisopropyl phosphofluoridate [18]. It modified only 1 from 28 serine residues of the enzyme. It means that this serine 
residue is very reactive. Location of Ser-195 in active site of chymotrypsin was confirmed in investigation carried out later, and the origin of its high reactivity was revealed. Diisopropyl phosphofluoridate was also successfully used for identification of a reactive serine residue in the active site of acetylcholinesterase [12].

To reveal reactive $\mathrm{SH}$-group in active site of various enzymes, different $\mathrm{SH}$-reagents were used, among them ${ }^{14} \mathrm{C}$-labeled $\mathrm{N}$-ethylmaleimide, iodoacetate, and iodoacetamide. Using these reagents, cysteines were revealed in the active sites of some dehydrogenase, cysteine protease, and other enzymes.

The second approach is the application of reactive substrate analogs. These compounds are structurally similar to the substrate but include chemically reactive groups, which can covalently bind to some amino acid residues. Substrate analogs are more specific than group-specific reagents. Tosyl-L-phenylalanine chloromethyl ketone, a substrate analog for chymotrypsin that is able to bind covalently with histidine residue and irreversibly inhibit enzyme, makes possible identification of Hys-57 in chymotrypsin active site [19].

\subsection{Natural enzyme inhibitors}

Many cellular enzyme inhibitors are proteins or peptides that specifically bind to and inhibit target enzymes. Numerous metabolic pathways are controlled by these specific compounds that are synthesized in organisms. Very interesting example of these inhibitors is protein serpins. It is a large family of proteins with similar structures. Most of them are inhibitors of chymotrypsin-like serine protease [20, 21].

Serine proteases (e.g., mentioned above chymotrypsin) possess a reactive serine residue in active site and have similar mechanisms of catalysis. Cleavage of peptide bond by these proteases is a two-step process. Reactive serine residue of the protease active site that looses $\mathrm{H}^{+}$and becomes nucleophilic one in the beginning of catalytic act attacks substrate peptide bond. This results in the release of new $\mathrm{N}$-terminal part of protein substrate (first product) and in the formation of a covalent ester bond between the enzyme and the second part of substrate (see Ref. [16]). The second step of catalysis of usual substrates leads to the hydrolysis of ester bond and to the release of the second product (C-terminal part of protein substrate). If serpin is cleaved by a serine protease, it undergoes conformational transition before the hydrolysis of ester bond between enzyme and the second part of substrate (serpin). The change of serpin conformation leads to the "freezing" of intermediate (complex of enzyme with covalently attached second part of serpin is retained for several days) [21]. Therefore, serpins are irreversible inhibitors with unusual mechanism of action. They have named "suicide inhibitors," because each serpin molecule can inactivate a single molecule of protease and kills itself during the process of protease inhibition.

Considering enzyme inhibitors we should keep in mind that many living organisms are in the state of "chemical war." Fungi are fighting with bacteria for food using antibiotics. Most immobile organisms like plants and some sea invertebrates use different poisons to defense themselves from being eaten; some vertebrates (like snakes) and invertebrates (e.g., bee and wasps) use poisons not only for defense but also to get food. If we will analyze the composition of these poisons, we can find in their content a lot of various enzyme inhibitors. They 
were selected during the evolution to stop many metabolic processes in organisms of victims that lead to their death.

Poisons of plants and invertebrates were used as medicine drugs during thousands of years. But only in the twentieth century, it became clear that the poisons contain various enzyme inhibitors as well as the blockers of some other biological molecules (channels, receptors, etc.) For example, bee venom includes melittin, peptide containing 28 amino acids. This peptide can interact with many enzymes suppressing their activities; in particular, it binds with protein calmodulin [22] that are activator of many enzymes. Special studies have shown that melittin structure imitates structure of some proteins (to be exact, some part of protein molecules) that can interact with target enzyme to provide their biological function [23].

Another example of natural inhibitors is cardiotonic steroids that were found initially in plants (digoxin, digitonin, ouabain) and in the mucus of toads (marinobufagenin, bufotoxin, etc.). These compounds are irreversible inhibitors of $\mathrm{Na}$,K-ATPase that is enzyme transporting $\mathrm{Na}^{+}$and $\mathrm{K}^{+}$through the plasma membrane of animals against the electrochemical gradients. In the end of the twentieth century, it was shown that cardiotonic steroids are presented in low concentrations in the blood of mammals including human beings. The increase of concentration of these compounds in the blood may be involved in the development of several cardiovascular and renal diseases including volume-expanded hypertension, chronic renal failure, and congestive heart failure [24].

Natural poisons are a powerful instrument for investigation of enzyme function, and analysis of their action is necessary for these studies. It might be also a model for design of new inhibitors and activators that will imitate natural compounds with such properties.

\subsection{Enzyme inhibitors as pharmaceutical agents}

We have mentioned above nonsteroidal anti-inflammatory drugs that are the inhibitors of cyclooxygenase. This group of compounds (the most prescribed drugs in the world, the oldest among them is aspirin) was successfully used for more than one century around the whole world for treatment of patients with fever, cardiovascular diseases, joint pain, etc. [5]. Among these drugs are both irreversible and reversible inhibitors that slow down production of prostaglandins that control many aspects of inflammation, smooth muscle contraction, and blood clotting. But there are many other groups of drugs that are by nature of inhibitors of some enzymes; the following groups of enzyme inhibitors are developed now by pharmaceutical companies and have very important therapeutic significances [24].

Inhibitors of angiotensin-converting enzyme (ACE). ACE catalyzes a conversion of inactive decapeptide angiotensin I into angiotensin II by the removal of a dipeptide from the C-terminus of angiotensin I. Angiotensin II is a powerful vasoconstrictor. Inhibition of ACE results in the decrease of angiotensin I concentration and in the relaxation of smooth muscles of vessels. Inhibitors of ACE are widely used as drugs for treatment of arterial hypertension [25].

Proton pump inhibitors (PPIs). Proton pump is an enzyme that is located in the plasma membrane of the parietal cells of stomach mucosa. It is a P-type ATPase that provides proton secretion from parietal cells in gastric cavity against the electrochemical gradient using energy of 
adenosine triphosphate (ATP) cleavage. PPIs are groups of substituted benzopyridines that in acid medium of stomach are converted into active sulfonamides interacting with cysteine residues of pump [26]. Therefore, PPIs are acid-activated prodrugs that are converted into drugs inside the organisms. PPIs are introduced in therapeutic practice in 80th years of the twentieth century. Since this time, the drugs are successfully used for treatment of gastritis, gastric and duodenal ulcer, and gastroesophageal reflux disease.

Statins represent a group of compounds that are analogs of mevalonic acid. They are inhibitors of 3-hydroxy-3-methylglutaryl-CoA reductase, an enzyme participating in cholesterol synthesis. Statins are used as drugs preventing or slowing the development of atherosclerosis [27]. Because of the existence of some adverse effects, statins may be recommended for patients that cannot achieve a decrease of cholesterol level in the blood through diet and changes in lifestyle.

Antibiotic penicillin covalently modifies the enzyme transpeptidase, thereby preventing the synthesis of bacterial cell walls and thus killing the bacteria [28].

Methotrexate is a structural analog of tetrahydrofolate, a coenzyme for the enzyme dihydrofolate reductase, which catalyzes necessarily step in the biosynthesis of purines and pyrimidines. Methotrexate binds to this enzyme approximately 1000-fold more tightly than the substrate and inhibits nucleotide base synthesis. It is used for cancer therapy [29].

New promising direction of anticancer therapy that is connected with suppression of protein kinases controlling the cellular response to DNA damage is now on the step of development. Selective inhibitors of these enzymes are now being tested in clinical trials in cancer patients [30].

Breakthrough in treatment of patients with acquired immune deficiency syndrome (AIDS) that is provoked by human immunodeficiency virus (HIV) was achieved recently using two different types of enzyme inhibitors. Nucleoside reverse transcriptase inhibitors and protease inhibitors are now recommended for treatment of patients with this decease. These inhibitors affect also some other viral infections and demonstrated anticancer activity. Presented here list of enzyme inhibitors that are used in therapy of numerous deceases that is far from being complete. But even mentioned above, points demonstrate how useful and important are therapeutic application of theoretical knowledge obtained as result of study of enzyme inhibitors [31].

Sciences around the world are involved in a search of new inhibitors of known enzymes that have therapeutic significance. An example of this complex research is a work devoted to design, synthesis, and study of new inhibitors of carbonic anhydrase, an enzyme that is involved in the development of such symptoms and deceases as edema, glaucoma, obesity, cancer, epilepsy, and osteoporosis (see Ref. [32]).

\section{Enzyme activators}

\subsection{Definition and mechanisms of action}

Enzyme activators are chemical compounds that increase a velocity of enzymatic reaction. Their actions are opposite to the effect of enzyme inhibitors. Among activators we can find ions, small organic molecules, as well as peptides, proteins, and lipids. 
There are many enzymes that are specifically and directly activated by small inorganic molecules, mainly by cations such as $\mathrm{Ca}^{2+}$ which is a the second messenger (among enzymes activated by $\mathrm{Ca}^{2+}$, we can find different regulatory enzymes, in particular phospholipases II, protein kinases $\mathrm{C}$, adenylyl cyclases, etc.). These enzymes usually have special site for $\mathrm{Ca}^{2+}$ binding; the binding of $\mathrm{Ca}^{2+}$ with it results in the change of enzyme conformation that increase enzyme activity [33].

Cations can bind not only with enzyme but also with the substrate increasing its affinity to the enzyme that activate enzyme. For example, magnesium ions interact with ATP or with other nucleotides that are negatively charged molecules, decreasing their charge that provides effective binding of nucleotides in substrate binding site of various enzymes and increasing their activity.

In some cases, activation of enzymes is due to the elimination of enzyme inhibitors. In total this effect looks as enzyme activation. Some cations including heavy metal cations inhibit definite enzymes. Small organic compounds like ethylene glycol-bis( $\beta$-aminoethyl ether $)-\mathrm{N}, \mathrm{N}, \mathrm{N}^{\prime}, \mathrm{N}^{\prime}$ tetraacetic acid (EGTA) and ethylenediaminetetraacetic acid (EDTA) that are known as chelating agents bind these inhibitory cations and by this way can eliminate their inhibitory effect.

Special group of activators can produce activation of target enzymes only after the formation of complex with another molecule. This complex, in turn, binds to enzyme and increases the velocity of enzymatic reaction. The most well-known example of such type of activators is Ca-binding protein calmodulin (calcium-modulated protein) that is expressed in all eukaryotic cells. Calmodulin is a small protein containing 148 amino acids (16.7 kDa). Its molecule consists of two symmetrical globular domains each with two Ca-binding motifs (EF-hand) located on $\mathrm{N}$ - and C-domains that are jointed by flexible linker. Flexibility of calmodulin molecule and the presence of nonpolar grooves in the middle part of the protein allow it to bind a large variety of proteins [33]. The binding of $\mathrm{Ca}^{2+}$ to calmodulin changes its conformation. These, in turn, make complex calmodulin- $\mathrm{Ca}^{2+}$ suitable for interaction with target enzymes (calmodulin-dependent protein kinases and phosphatases,Ca-ATPase of plasma membrane, etc.), by this manner increasing their activity. Therefore calmodulin is considered as a participant of calcium signal transduction pathway that provides enforcing and prolongation of the effect of $\mathrm{Ca}^{2+}$ as a second messenger [34].

\subsection{Allosteric enzyme modulators}

Inhibitors and activators (modulators) that bind to enzymes not in the active site but in special center located far enough from it have name allosteric modulators. Their binding to allosteric sites induces the change of enzyme conformation that affects both the structure of active site and enzyme conformational mobility leading to the decrease or to the increase of enzyme activity. Just as enzyme active site is specific in relation to substrate, the allosteric site is specific to its modulator [16].

Many metabolic pathways are regulated through the action of allosteric modulators. Enzymes in metabolic pathways work sequentially, and in such pathways, a product of one reaction becomes a substrate for the next one. The rate of whole pathway is limited by the rate of the lowest reaction. Allosteric regulators often are a final product of whole metabolic pathway 
that activates enzymes catalyzing a limiting step of the whole pathway. Enzymes in a metabolic pathway can be inhibited or activated by downstream products. This regulation represents negative and positive feedbacks that slow metabolic pathway when the final product is produced in large amounts or accelerate it when a final product is presented in low concentration. Therefore, allosteric modulators are important participants of such negative and positive feedbacks in metabolic pathways or between them making metabolism self-controlled.

For example, ATP and citrate are inhibitors of phosphofructokinase that is a key enzyme of glycolytic pathway. One product of glycolysis is ATP. Another product is pyruvate that after the conversion into acetyl-CoA is condensed with citrate opening cycle of citrate acids (Krebs cycle). Reactions of this cycle produce reduced nicotinamide adenine dinucleotide reduced (NADH) and flavinadeninidinucleotide reduced (FADH2), oxidation of which is coupled with massive production of ATP in mitochondria. Availability of ATP or citrate inhibits glycolysis preventing glucose oxidation (negative feedback). Inhibition of phosphofructokinase by ATP or by citrate occurs by allosteric manner [35]. Described negative feedback control maintains a steady concentration of ATP in the cell. It should be noted also that metabolic pathways are regulated not only through inhibition but also through activation of the key enzymes. Mentioned above phosphofructokinase is activated by adenosine diphosphate (ADP), adenosine monophosphate (AMP), and fructose-2,6-bisphospate that represents positive feedback control.

Enzymes that are regulated by allosteric modulators are usually presented by several interacting subunits (they are called oligomers). A very interesting example of regulation of the activity of oligomeric enzymes is c-AMP-dependent protein kinase that is an important regulatory enzyme participating in the phosphorylation of serine and threonine residues of target proteins changing by this way their activity. This enzyme consists of four subunits; two of them are catalytic and two are regulatory. Cyclic AMP (c-AMP) is allosteric activator of this enzyme. Catalytic subunit being bound to the regulatory one is inactive. Binding of two c-AMP molecules to allosteric sites of each regulatory subunit induces their conformation transition that results in dissociation of the tetrameric complex and in activation of catalytic subunits [36]. Decrease of c-AMP concentration leads to its dissociation from the allosteric site and to association of regulatory and catalytic subunits with subsequent inactivation of catalytic subunits. By this way, c-AMP activity depends upon the c-AMP concentration in the cell.

\section{Conclusions}

Enzyme inhibitors and activators are a number of various chemical compounds that can slow down (or even stop) and activate enzymes, natural protein catalysts. They include inorganic compounds (often anions), different organic compounds (mainly containing reactive groups that can modify amino acids of protein), natural proteins, lipids, and carbohydrates. Mechanism of inhibitor and activator action on the enzyme activity includes a step of their binding to the enzyme, after which a step of the change of enzyme conformation often follows.

Inhibitors are a good tool for study of enzyme reaction mechanisms. Many natural inhibitors especially obtained from plants and invertebrates often imitate natural proteins or some of 
their motifs that participate in the protein-protein interactions in the cell that are important for metabolic regulation. Among enzyme activators and inhibitors, one can highlight a group of allosteric modulators that participate in feedback regulation of metabolic pathways. And finally, we should note a practical significance of enzyme inhibitors that are a base for the design of different classes of pharmaceutical drugs, pesticides, and insecticides.

\section{Author details}

Olga D. Lopina

Address all correspondence to: od_lopina@mail.ru

Department of Biochemistry, School of Biology, M.V. Lomonosov Moscow State University, Moscow, Russia

\section{References}

[1] McAuley M, Timson DJ. , 2017; 181(1):83-90.

[2] Yang LW, Bahar I. Coupling between catalytic site and collective dynamics: a requirement for mechanochemical activity of enzymes. Structure. 2005; 13:893-904. DOI: 10.1016/j.str. 2005.03.015.

[3] Herschlag D, Natarajan A. Fundamental challenges in mechanistic enzymology: progress toward understanding the rate enhancement of enzyme. Biochemistry. 2013; 52:2050-67. DOI: 10.1021/bi4000113.

[4] Nevinsky GA, Buneva VN. Natural catalytic antibodies in norm, autoimmune, viral, and bacterial diseases. Sci World J. 2010; 10:1203-33. DOI: 10.1100/tsw.2010.98.

[5] Simon LS. Nonsteroidal antiinflammatory drugs and their effects. J Clin Rheumatol. 1996; 2(3):135-40. PMID: 19078048.

[6] Cleland WW. The kinetics of enzyme-catalyzed reactions with two or more substrates or products. II. Inhibition: nomenclature and theory. Biochim Biophys Acta. 1963; 67:17387. DOI: 10.1016/0926-6569(63)90226-8.

[7] Malito E, Ralat LA, Manolopoulou M, Tsay JL, Wadlington NL, Tang W-J. Molecular bases for the recognition of short peptide substrates and cysteine-directed modifications of human insulin-degrading enzyme. Biochemistry. 2008; 47(48):12822-34. DOI: 10.1021/ bi801192h.

[8] Malhotra OP, Srivastava DK, Kayastha AM, Srinivasan. Inactivation of glyceraldehyde3-phosphate dehydrogenase with SH-reagents and its relationship to the protein quaternary structure. Indian J Biochem Biophys. 1993; 30(5):264-9. PMID: 8144169. 
[9] Ogawa H, Shinoda T, Cornelius F, Toyoshima C. Crystal structure of the sodium potassium pump $\left(\mathrm{Na}^{+}, \mathrm{K}^{+}\right.$-ATPase) with bound potassium and ouabain. Proc Natl Acad Sci. 2009; 106(3):13742-47. DOI: 10.1073/pnas.0907054106.

[10] Oosterbaan RA, Kunst P, Cohen JA. The nature of the reaction between diisoprophylfluorophosphate and chymotrypsin. Biochim Biophys Acta. 1955; 16(2):299-300.

[11] Schmidt AE, Sun MF, Ogawa T, Bajaj SP, Gailani D. Functional role of residue 193 (chymotrypsin numbering) in serine proteases: influence of side chain length and betabranching on the catalytic activity of blood coagulation factor XIa. Biochemistry. 2008; 47(5):1326-35. DOI: 10.1021/bi701594j.

[12] Leuzinger W. The number of catalytic sites in acetylcholinesterase. Biochem J. 1971; 123(2):139-41.

[13] Lecomte M, Laneuville O, Ji C, DeWitt DL, Smith WL. Acetylation of human prostaglandin endoperoxide synthase-2 (cyclooxygenase-2) by aspirin. J Biol Chem. 1994; 269(18):13207-15. PMID: 8175750.

[14] Berg JM, Tymoczko JL, Stryer L. Biochemistry. 7th ed. W.H. Freeman and Company, New-York, USA. 2012: 229.

[15] Colović MB, Krstić DZ, Lazarević-Pašti TD, Bondžić AM, Vasić VM. Acetylcholinesterase inhibitors: pharmacology and toxicology. Curr Neuropharmacol. 2013; 11(3):315-35. DOI: $10.2174 / 1570159 X 11311030006$.

[16] Nelson DL, Cox MM. Lehninger Principles of Biochemistry. 4th ed. 2005: 1216. DOI: 10.1002/bmb.2005.494033010419.

[17] Krowarsch D, Cierpicki T, Jelen F, Otlewski J. Canonical protein inhibitors of serine proteases. Cell Mol Life Sci. 2003; 60(11):2427-44. DOI: 10.1007/s00018-003-3120-x.

[18] Ogata S, Misumi Y, Tsuji E, Takami N, Oda K, Ikehara Y. Identification of the active site residues in dipeptidyl peptidase IV by affinity labeling and site-directed mutagenesis. Biochemistry. 1992; 31(9):2582-7. PMID: 1347701.

[19] Tsilikounas E, Rao T, Gutheil WG, Bachovchin WW. ${ }^{15} \mathrm{~N}$ and ${ }^{1} \mathrm{H}$ NMR spectroscopy of the catalytic histidine in chloromethyl ketone-inhibited complexes of serine proteases. Biochemistry. 1996; 35(7):2437-44. DOI: 10.1021/bi9513968.

[20] Janciauskiene S. Conformational properties of serine proteinase inhibitors (serpins) confer multiple pathophysiological roles. Biochim Biophys Acta. 2001; 1535(3):221-35.

[21] Pike RN, Bottomley SP, Irving JA, Bird PI. Serpins: finely balanced conformational traps. IUBMB Life. 2002; 54(1):1-7. DOI: 10.1080/15216540213825.

[22] Kataoka M, Head JF, Seaton BA, Melittin binding causes a large calcium-dependent conformational change in calmodulin. Proc Natl Acad Sci USA. 1989; 86:6944-8.

[23] Raynor RL, Zheng B, Kuo JF. Membrane interactions of amphiphilic polypeptides mastoparan, melittin, polymyxin B, and cardiotoxin. Differential inhibition of protein kinase C, $\mathrm{Ca}^{2+} /$ calmodulin-dependent protein kinase II and synaptosomal membrane $\mathrm{Na}, \mathrm{K}-\mathrm{ATPase}$, and $\mathrm{Na}^{+}$pump and differentiation of HL60 cells. J Biol Chem. 1991; 266(5):2753-8. PMID: 1847132. 
[24] Buckalew VM. Endogenous digitalis-like factors: an overview of the history. Front Endocrinol (Lausanne). 2015; 6:49. DOI: 10.3389/fendo.2015.00049.

[25] Hsiao FC, Tung YC, Chou SH, Wu LS, Lin CP, Wang CL, Lin YS, Chang CJ, Chu PH. Fixed-dose combinations of renin-angiotensin system inhibitors and calcium channel blockers in the treatment of hypertension: a comparison of angiotensin receptor blockers and angiotensin-converting enzyme inhibitors. Medicine (Baltimore). 2015; 94(51):e2355. DOI: 10.1097/MD.0000000000002355.

[26] Jain KS, Shah AK, Bariwal J, Shelke SM, Kale AP, Jagtap JR, Bhosale AV. Recent advances in proton pump inhibitors and management of acid-peptic disorders. Bioorg Med Chem. 2007; 15(3):1181-205.

[27] Satoh M, Takahashi Y, Tabuchi T, Minami Y, Tamada M, Takahashi K, Itoh T, Morino Y, Nakamura M. Cellular and molecular mechanisms of statins: an update on pleiotropic effects. Clin Sci (Lond). 2015; 129(2):93-105. DOI: 10.1042/CS20150027.

[28] Katz AH, Caufield CE. Structure-based design approaches to cell wall biosynthesis inhibitors. Curr Pharm Des. 2003; 9(11):857-66. DOI: 10.2174/1381612033455305.

[29] McGuire JJ. Anticancer antifolates: current status and future directions. Curr Pharm Des. 2003; 9(31):2593-613. DOI: 10.2174/1381612033453712.

[30] Garrett MD, Collins I. Anticancer therapy with checkpoint inhibitors: what, where and when? Trends Pharmacol Sci. 2011; 32(5):308-16. DOI: 10.1016/j.tips.2011.02.014.

[31] Rutherford GW, Horvath H. Dolutegravir plus two nucleoside reverse transcriptase inhibitors versus efavirenz plus two nucleoside reverse transcriptase inhibitors as initial antiretroviral therapy for people with HIV: a systematic review. PLoS One. 2016; 11(10):e0162775. DOI: 10.1371/journal.pone.0162775.

[32] Fidan I, Salmas RE, Arslan M, Sentürk M, Durdag S, Ekinci D, Sentürk E, Cosgun S, Supuran CT. Carbonic anhydrase inhibitors: design, synthesis, kinetic, docking and molecular dynamics analysis of novel glycine and phenylalanine sulfonamide derivatives. Bioorg Med Chem. 2015; 23(23):7353-8. DOI: 10.1016/j.bmc.2015.10.009.

[33] Villarroel A, Taglialatela M, Bernardo-Seisdedos G, Alaimo A, Agirre J, Alberdi A, Gomis-Perez C, Soldovieri MV, Ambrosino P, Malo C, Areso P. The ever changing moods of calmodulin: how structural plasticity entails transductional adaptability. J Mol Biol. 2014; 426(15):2717-35. DOI: 10.1016/j.jmb.2014.05.016.

[34] Brini M, Carafoli E. Calcium signalling: a historical account, recent developments and future perspectives. Cell Mol Life Sci. 2000; 57(3):354-70. DOI: 10.1007/PL00000698.

[35] Sola-Penna M, Da Silva D, Coelho WS, Marinho-Carvalho MM, Zancan P. Regulation of mammalian muscle type 6-phosphofructo-1-kinase and its implication for the control of the metabolism. IUBMB Life. 2010; 62(11):791-6. DOI: 10.1002/iub.393.

[36] Turnham RE, Scott JD. Protein kinase A catalytic subunit isoform PRKACA; history, function and physiology. Gene. 2016; 577(2):101-8. DOI: 10.1016/j.gene.2015.11.052. 
